\title{
COM \\ Exploration of social cues in technology-mediated science communication: a multidiscipline analysis on 'Ask Me Anything (AMA)' sessions in Reddit r/science
}

\section{Ying Tang, Jessica M. Abbazio, Khe Foon Hew and Noriko Hara}

\begin{abstract}
Social cues are used to facilitate online science communication, yet little is known about how they may play a role in online public engagement with science sites. This mixed-method study investigates $\mathrm{r} / \mathrm{science}$ Ask Me Anything (AMA) sessions on Reddit through content analysis and an online survey to identify the types and variations of social cues manifested in six $\mathrm{r} /$ science AMAs across varying disciplines. The study's contributions are twofold. One is to investigate social cue uses in online science communication; the other is to develop a coding scheme for social cues that incorporates both positive and negative social cues in the analysis.
\end{abstract}

Keywords

DOI

Public engagement with science and technology; Public understanding of science and technology

https://doi.org/10.22323/2.20070204

Submitted: 11th June 2021

Accepted: 21st September 2021

Published: 22nd November 2021

Science communication aims to promote the following five responses from laypeople: "awareness, enjoyment, interest, opinion, and understanding" [Burns, $\mathrm{O}^{\prime}$ Connor and Stocklmayer, 2003]. It encompasses activities in which scientists provide the general public with scientific knowledge so that lay individuals can make informed decisions, develop an interest, and understand the content, processes, and social factors of science. By informing the public, scientists inspire non-expert interest and participation in scientific careers and activities [Davies, 2008]. Science communication also aims to address issues of public discontent with expert knowledge and loss of trust [Gauchat, 2012]. Restoring public trust is important because scientists are sources on which policy makers, legislators, activists, and the public rely to help them make well-informed decisions [Wilholt, 2013].

Science communication not only functions to serve the lay public's interest, but also benefits scientists. The former group may develop a more critical understanding of science by having complex issues explained in lay terms [Burns, $\mathrm{O}^{\prime}$ Connor and 
Stocklmayer, 2003]. Due to the gaps between specialists and non-specialists in each field, "laypeople" is a multifaceted definition [Lévy-Leblond, 1992]. As a scientist's knowledge is comparable to that of a layperson outside their professional domain, science communication nurtures a cross-disciplinary communicative channel, improving peer networking among diversely experienced scientists.

Past science communication has been largely one-directional. Recently, scientists have become more involved in activities requiring public participation, and Reddit is one such platform that affords two-way interaction between scientists and laypeople. Reddit is a massive social sharing website divided into thousands of specialized discussion boards (subreddits) stylized as reddit.com $/ \mathrm{r} /$ [subreddit]. Redditors subscribe to subreddits for information exposure and exchange, and upvote or downvote comments. The "Ask Me Anything (AMA)" sessions in Reddit's Science subreddit (herein called $\mathrm{r}$ /science) are one group of social Q\&A venues which democratizes the communication between science and society [Einsiedel, 2014]. In particular, Reddit AMA differs from other Q\&A venues in that it allows social interaction but also features expert involvement, making it a unique platform to establish a communicative channel between scientists and the general audience. However, while Reddit has grown in popularity [Weninger, Zhu and Han, 2013], our understanding of its social Q\&A features remains limited [Hara, Abbazio and Perkins, 2019]. Thus, a better descriptive sense of scientists' use of social media like Reddit is necessary [Dudo, 2015].

Specifically, this study responds to these trends by investigating the use of social cues (SCs) in the r/science AMA community. SCs reflect an individual's feelings and involvement when engaging with others [Chen and Chiu, 2008], and the civility and welcoming nature of an online community can help the community thrive [Hara, Shachaf and Hew, 2010]. We are interested in how scientists present themselves socially in online Q\&A settings, and how scientists' use of SCs affect their audiences. According to Oh [2012], social engagement is a critical reason for participating in social Q\&A services, as users spontaneously construct a community with shared interest and desire for interaction [Jin et al., 2015]. A closer examination of the social nature of online science Q\&As helps us better understand how people project themselves socially in virtual settings and how we can improve science communication by strategically manipulating the environment and structures of online science conversation.

Our goal is to contribute an empirical understanding of SCs' manifestations in tandem with technology-mediated science communication practices in online social networking sites, extending our comprehension of $r$ /science AMA communities in four ways. First, we developed a framework examining both positive and negative SCs occurring in AMA comments. This framework is based on extant literature [e.g., Jeng et al., 2017] and supplemented with specific indicators generated in a grounded approach. Second, we analyzed the occurrences of SCs across six scientific disciplines (astronomy, biology, chemistry, environment science, geology, and medicine). Investigations of multiple disciplines generally produce wider and more reliable results [Baxter and Jack, 2008]. Third, we described how scientists employed SCs in r/science AMAs. No previous studies have examined how scientists present themselves to laypeople in open, social Q\&A venues. Fourth, we examined how guest scientists' use of SCs impacts engagement by comparing the frequencies and types of SCs used in $\mathrm{r} /$ science 
AMAs. Understanding the influence of scientists' SCs on participants' involvement can help promote science communication on social technological platforms.

We focused on three specific research questions:

- RQ1: What kinds of SCs are manifested in the r/science AMA comments?

- RQ2: What variations of SCs are present across the different $r$ /science AMA sessions?

- RQ3: How does the use of SCs by guests affect that of audiences in the $\mathrm{r} /$ science AMA sessions?

\section{Technology-mediated science communication}

While technology-mediated science communication via the Internet is omnipresent and convenient, its full potential has not yet been reached [Su et al., 2017], and two-way interaction is often limited. At the same time, when it comes to social media platforms (e.g., Facebook, Twitter), scientists can communicate directly with audiences, realizing a maximum potential for public engagement [Young, Tully and Dalrymple, 2018].

In recent years, the influence of social media on science communication has grown beyond traditional news media. Social media have increasingly demonstrated agenda-setting abilities, as seen in the information flow in climate change discourse on Twitter from 2015 to 2017 [Jones-Jang et al., 2020]. Social media use is more positively associated with reliance on science than traditional news use, possibly due to expanding networks, users' trust in social contacts, and direct access to these platforms' sources [Huber et al., 2019]. Social media communication has also widened the exposure of scientists' work, resulting in more interdisciplinary support and an increase in the value of their reputation and external funding [Jia et al., 2017]. Social media-based communication not only facilitates peer networking among scientists, but also connects the science community with laypeople [Jünger and Fähnrich, 2020].

That being said, the lack of social media gatekeeping and quick-spreading opinions on science topics [Jang et al., 2019] are catalysts for hearsay and inaccurate information; scientific misinformation can be easily generated through image manipulation or decontextualization [Rigutto, 2017]. Additionally, uncivil comments on scientific news articles lead to biased interpretations of the news content, ultimately necessitating moderation of online comments to alleviate possible negative effects [Yeo et al., 2019].

Despite the involvement of scientific institutions in science communication, the dialogic potential of social media, which is currently viewed as a means of one-way information dissemination [Lee et al., 2015], has not been fully utilized.

\section{Reddit $A M A$ as an expert-driven social QEA service}

The Internet is the largest repository of information on virtually any subject [Recabarren, Nussbaum and Leiva, 2008]. While search engines function as 
gateways to information, interactions through Q\&A sites are gaining popularity [Shah, Kitzie and Choi, 2014]. One type of Q\&A site where tailored answers are given is the "social Q\&A service, [where] anyone can answer" [Gazan, 2011, p. 2302], in which questions are posted to large open communities or social networking groups. Users spontaneously construct a social connection among participants with shared interests and desire for interaction [Jin et al., 2015] by commenting on or rating the answers, further tapping into the aggregated wisdom of crowds. Shah, Kitzie and Choi [2014] defined the following three key features of social Q\&A:

1. A mechanism of phrasing requests in natural language.

2. A place of public participation and response.

3. A community contributing to a collected wisdom.

Reddit, a social Q\&A site where participants ask questions, receive individualized answers, exchange ideas in a threaded list, and collaboratively choose the best answer [Choi, Kitzie and Shah, 2012] by a mechanism of upvoting and downvoting, has built a reputation for itself over recent years. Instead of creating a social network based on interpersonal relationships like Facebook and Twitter, Reddit caters to audiences seeking information about particular topics. It provides specific technological affordances, such as upvoting/downvoting and committed moderators, who play a fundamental role in fostering the community by enacting the content policy, deleting inappropriate posts, and banning policy violators [Matias, 2019]. These mechanisms are different from other social media platforms, as well as face-to-face $(\mathrm{FtF})$ venues.

A common criticism of social Q\&A is the answer quality, as it depends on the wisdom of crowds rather than expert opinions [Shah, Kitzie and Choi, 2014]. Reddit AMAs - interactive forums for experts and lay audiences - have addressed this concern, by presenting a unique, expert-driven form of social Q\&A. Reddit AMAs highlight expert knowledge while encouraging active interactions among participants [Hara, Abbazio and Perkins, 2019]. Guests field questions about anything in the expert domain, and then lively discussions ensue. Due to guests' credentials and ability to disregard irrelevant questions, the quality of responses is guaranteed.

\section{Online social cues}

Verbal and nonverbal SCs are used to reflect personal feelings and involvement in online interactions [Chen and Chiu, 2008], strengthening or mitigating the intensity of messages [Tang and Hew, 2019], and allowing users to come off as "real" [Garrison, Anderson and Archer, 1999]. Previously observed SCs include emotional and affective expressions like anecdotal self-disclosure, sharing of personal information, and humor [Rourke et al., 1999]. The use of SCs as factors in the quality of interaction and predictors of satisfaction [Gunawardena, 1995] have been examined in different online communication environments, including learning forums [Chen, Chiu and Wang, 2012], dating sites [Kotlyar and Ariely, 2013], and Q\&A sites [Jeng et al., 2017]. 
The effects of SCs on interactions are likely to be similar within FtF and online contexts [Chen and Chiu, 2008]. Positive SCs strengthen the level of positivity in one's expressions or alleviate the threat of negative utterances; negative SCs express disagreement or negativity. In FtF settings, SCs are often expressed in visual or relational cues such as facial expressions and tonal variation, while the lack of visual cues in online environments has inspired the use of emotional icons (e.g., Yes :)) or punctuation (e.g., I disagree!!!) to mediate social relationships [Walther, 1992; Walther, 1996].

Previous studies have exclusively observed the positive aspects of SCs in online communication, which Kling, Rosenbaum and Sawyer [2005] would describe as the "standard model" based on researchers' assumptions. Few prior studies have examined the negative aspects of SCs. In fact, the anonymity in online environments may result in more disagreement and negative emotions [Reinig and Mejias, 2004]. Negative SCs, such as discouraging expressions and flaming attacks, are worthy of further exploration.

\section{Social cues in technology-mediated science communication}

Previous studies have examined the use of positive SCs in technology-mediated science communication. Jeng et al. [2017] identified three types of positive SCs (Comfort, Politeness, and Open for a further contact) in a ResearchGate Q\&A study. In the discipline of astrophysics, the total percentage of messages containing SCs was $24.8 \%$ lower than in two other observed non-science disciplines. Politeness occurred much more than the other SCs in all three disciplines, supporting Tang et al.'s [2019] finding that in a live online Q\&A session on archaeology, socializing posts accounted for $19 \%$ of the total SCs, and appreciation expression was the most frequent SC. These posts encouraged a lively environment and sharing of insider knowledge.

Marsh [2016] examined the use of humor in technology-mediated science communication on Facebook and Reddit. Although r/science policy prohibits jokes, ${ }^{1}$ there is a positive correlation between humorous comments' upvotes and their promotion on Reddit's main page. Marsh also observed that posts on the Facebook page "I Fucking Love Science", one of the top three most engaged Facebook pages, were frequently humorous. However, humor may not always effectively facilitate science communication [Riesch, 2015]. While jokes targeted for ingroups (i.e. scientists) can influence "community- and identity-building... [and] set up and strengthen the boundaries", [Riesch, 2015, p. 773] they can also be used to distinguish ingroups from outgroups (i.e., non-scientists), potentially impacting science communication negatively.

Thus far, little is known about the features and effects of trolling in science communication. Trolling is a "set of diverse pseudo-sincere behaviors that draw attention, ranging from anger at provocation to appreciation of humor to recognition of serious opinions" [Sanfilippo, Yang and Fichman, 2017, p. 2314]. Considering the complexity and variations of trolling, context should not be overlooked in researching this online behavior. Wikipedia trolls are mainly motivated by boredom and a desire for attention and revenge, engaging in

\footnotetext{
${ }^{1}$ The rule, "No jokes or memes", was specified as of July 10, 2020.
} 
repetitive, intentional, and harmful actions that inhibit the development of communities [Shachaf and Hara, 2010], while video game trolls engage in griefing, sexism/racism, and faking/intentional fallacy [Thacker and Griffiths, 2012].

Another SC that is not adequately addressed in the literature concerning science communication is the use of argumentative or sarcastic tone. Goodwin and Dahlstrom [2014] suggested that to gain trust, climate scientists should engage doubtful audiences, adopting open attitudes and inviting criticism of their work. However, the intensity and deviancy of disembodied argumentative messages could be destructive to the participative climate and norms of network usage [Mabry, 1997]. Satirical or ironic utterances are used to intentionally wound recipients' feelings, usually reflecting a negative attitude [Kreuz and Glucksberg, 1989]. A limited presence of sarcasm may still detract social media discussions from healthy public science communication [Ziegele and Jost, 2020]. Therefore, investigating the use and influence of sarcasm is important.

While previous studies have demonstrated the various types and frequencies of SCs, no prior studies appear to have examined the presence and roles of specific SCs in technology-mediated science communication. This study aims to bridge this gap, exploring the manifestations of SCs and their variance among different guests within $\mathrm{r}$ /science AMA sessions.

Methods

$\mathrm{r}$ /science AMA is an intriguing example of a technology-mediated science communication Q\&A service. $r$ /science AMAs were established in January 2014 by chemist Nathan Allen to facilitate informal conversations between scientists and laypeople. From October 2016 to June 2017, there were approximately 18 million $\mathrm{r} /$ science subscribers, and the range of posts in each $\mathrm{r}$ /science AMA were between 17 and 2469. These AMA sessions were organized by $\mathrm{r} /$ science moderators who invited one or multiple featured guest scientists of various disciplines, and participants could ask them anything.

\section{Data collection and analysis}

Content analysis of AMA comments was the primary method for this study, and responses to a survey of $r$ /science AMA guests provided supplemental data. The comments, excluding deletions, were collected from $\mathrm{r}$ /science AMA sessions in six disciplines, chosen based on three criteria: discipline, number of comments, and time period. We selected four traditional disciplines (astronomy, biology, chemistry, and geology) that appeared repeatedly on $\mathrm{r}$ /science AMAs, and two other frequently-addressed disciplines (environmental science and medicine). Due to the nature of manual coding, we selected sessions that included approximately 200-300 comments. The number of comments in all AMAs dating from this period ranged from 0 and 5647, averaging 106.3. The timeframe was October 20, 2016 to June 27, 2017, 4 months prior to the survey distribution.

We chose the following $\mathrm{r}$ /science AMA sessions:

- AMA \#1: Astronomy (NASA's space communications)

- AMA \#2: Biology (Bird genetics) 
Table 1. Summary of sampled AMAs for the study [adapted from reference removed for review].

\begin{tabular}{lcccccc}
\hline & $A M A \# 1$ & $A M A \# 2$ & $A M A \# 3$ & $A M A \# 4$ & $A M A \# 5$ & $A M A \# 6$ \\
\hline Total \# of comments & 227 & 203 & 236 & 248 & 198 & 251 \\
\# of guests & 5 & 2 & 1 & 2 & 1 & 6 \\
Question response rate & $49.5 \%$ & $70.2 \%$ & $18.4 \%$ & $57.1 \%$ & $45.6 \%$ & $74.3 \%$ \\
\hline
\end{tabular}

- AMA \#3: Chemistry (Biomedical nanomaterials)

- AMA \#4: Environmental Science (Climate change)

- AMA \#5: Geology (Snow and ice)

- AMA \#6: Medicine (Wound dressing)

Table 1 presents a summary of sampled AMAs. The number of comments ranged from 203 to 251, averaging 227.2, the number of guest scientists in each session ranged between 1 and 6 , and the percentage of users' answered questions ranged from $18.4 \%$ to $74.3 \%$. In each AMA that included multiple guest scientists, the guests shared a single joint account to interact with the audience.

To develop the codebook, we first analyzed the content of a single AMA (Geology). We employed three SC codes from Jeng et al. [2017], modified the code definitions, and appended new codes to better reflect the content. When coding uncertainty arose, we revised the code's definition and retested all codes before applying the codebook to other AMAs.

The SC category in Jeng et al.'s codebook included three codes: Comfort, Politeness, and Open for a further contact. Due to the difficulty of distinguishing comfort from politeness, we combined the two. We kept the category Open for a further contact, but renamed it Inviting further contact to clarify the message's intended purpose. Four additional codes were developed based on the data to reflect better contextual coding: Explicit emotional expression, Argumentative or sarcastic tone, Trolling, and Humor. We further analyzed SC2 based on the following sub-categories: Emoticons (e.g., sad face mark); Internet-specific abbreviations (e.g., LOL); and Emphasized text (e.g., capitalization).

Whenever discrepancies occurred, we reviewed the thought processes while coding and discussed possible clarifications due to potentially different interpretations. Any previously missed concepts drove us to reevaluate code definitions. We tested new versions of code definitions by coding a different AMA and assessing the outcomes. The final codebook is summarized in Table 2.

The intercoder reliability ranged from 0.66 and 1 in Cohen's Kappa. According to McHugh's [2012] statement that inter-coder reliability ratings between 0.61 and 0.80 are considered substantial, and between 0.81 and 1.0 are considered almost perfect agreement, our codebook was reliable. Due to the varied numbers of comments coded for the six selected AMAs, we presented and compared their code percentages, calculated based on the number of SCs divided by the total number of posts. If more than one of the same SC appeared in a post, we only tagged that post 
Table 2. Codebook for social cues.

\begin{tabular}{|c|c|c|}
\hline Codes & Operationalization of codes & Example posts \\
\hline $\begin{array}{l}\text { SC1. } \\
\text { Politeness and } \\
\text { comfort }\end{array}$ & $\begin{array}{l}\text { Comment contains short and warm } \\
\text { greeting or polite phrasing that } \\
\text { communicates respect; can be attached to } \\
\text { either positive or negative feedback; this } \\
\text { category does not include salutations like } \\
\text { "hi" or "good morning" }\end{array}$ & $\begin{array}{l}\text { "Thank you for clearing this up } \\
\text { for me, and very well } \\
\text { explained!"; "All the best"; } \\
\text { "A follow up question, if you } \\
\text { don't mind..." }\end{array}$ \\
\hline $\begin{array}{l}\text { SC2. } \\
\text { Explicit } \\
\text { emotional } \\
\text { expression }\end{array}$ & $\begin{array}{l}\text { Comment includes Internet-specific } \\
\text { punctuation that emphasizes emotion }\end{array}$ & $\begin{array}{l}\text { Expressive punctuation ("What } \\
\text { is the } \sim \text { coolest } \sim \text { thing that you've } \\
\text { seen in your research?"), } \\
\text { italicized text, capitalization } \\
\text { ("Any discussion of climate } \\
\text { engineering MUST be global"), } \\
\text { emoticons, "haha" }\end{array}$ \\
\hline $\begin{array}{l}\text { SC3. } \\
\text { Argumentative } \\
\text { or sarcastic tone }\end{array}$ & $\begin{array}{l}\text { Comment contains constructive feedback } \\
\text { that is argumentative or sarcastic in tone; } \\
\text { this feedback furthers discussion in } \\
\text { response to content in previous } \\
\text { comments; commenter is arguing with the } \\
\text { intention to engage or in support of their } \\
\text { point; sarcasm is defined as something } \\
\text { that can only be interpreted as being } \\
\text { meant to be sarcastic (excludes situations } \\
\text { of poor wording) }\end{array}$ & $\begin{array}{l}\text { "Yea. So this guy got to go on } \\
\text { trips and do 'research' to } \\
\text { conclude an obvious } \\
\text { phenomenon"; "Really? No } \\
\text { clue? Here's a tip. He won't } \\
\text { listen to you." }\end{array}$ \\
\hline $\begin{array}{l}\text { SC4. } \\
\text { Inviting further } \\
\text { contact }\end{array}$ & $\begin{array}{l}\text { Comment contains a responder's contact } \\
\text { information or invites others to contact } \\
\text { them to engage in further discourse; } \\
\text { comment suggests establishing contact } \\
\text { with a third party and provides } \\
\text { identifying information }\end{array}$ & $\begin{array}{l}\text { "Sounds very interesting! I am } \\
\text { keen to hear more about this. } \\
\text { Please drop me an email" }\end{array}$ \\
\hline $\begin{array}{l}\text { SC5. } \\
\text { Trolling }\end{array}$ & $\begin{array}{l}\text { Comment does harm toward the sense of } \\
\text { community by attempting to derail the } \\
\text { conversation; comment is off-topic in a } \\
\text { manner that seems meant to confuse, } \\
\text { fluster, or unsettle guests and participants }\end{array}$ & $\begin{array}{l}\text { "Where are you hiding the } \\
\text { aliens?"; “Why do my spigetti o's } \\
\text { keep making lightning?"; }\end{array}$ \\
\hline $\begin{array}{l}\text { SC6. } \\
\text { Humor }\end{array}$ & $\begin{array}{l}\text { Commenter interjects humorous content } \\
\text { into their comment/question; intention is } \\
\text { to amuse the reader and build a rapport }\end{array}$ & $\begin{array}{l}\text { "Is the Bath short for something? } \\
\text { And if so, how are your } \\
\text { archrivals at the University of } \\
\text { Shower doing? :]"; Participant: } \\
\text { "What is the air-speed velocity of } \\
\text { an unladen swallow?" Guest: } \\
\text { "faster than a laden swallow" }\end{array}$ \\
\hline
\end{tabular}

with the relevant code once. To answer RQ3, we separated the guest scientists' and participants' SCs and counted the frequencies of each SC used in each AMA. We further calculated the percentages by dividing the number of each SC by the total number of posts.

As part of a larger study [Hara, Abbazio and Perkins, 2019], the data from a June 2017 survey of $r$ /science AMA guest scientists were used to triangulate the findings from the content analysis [Denzin, 2007]. Three hundred and fifteen scientists who hosted $\mathrm{r}$ /science AMA during the period of October-December in 2016 were contacted via email with invitations to participate in a survey through Qualtrics. Seventy of the 315 surveys were completed. The full survey contained 26 questions including demographic information, inquiries about the experience of 


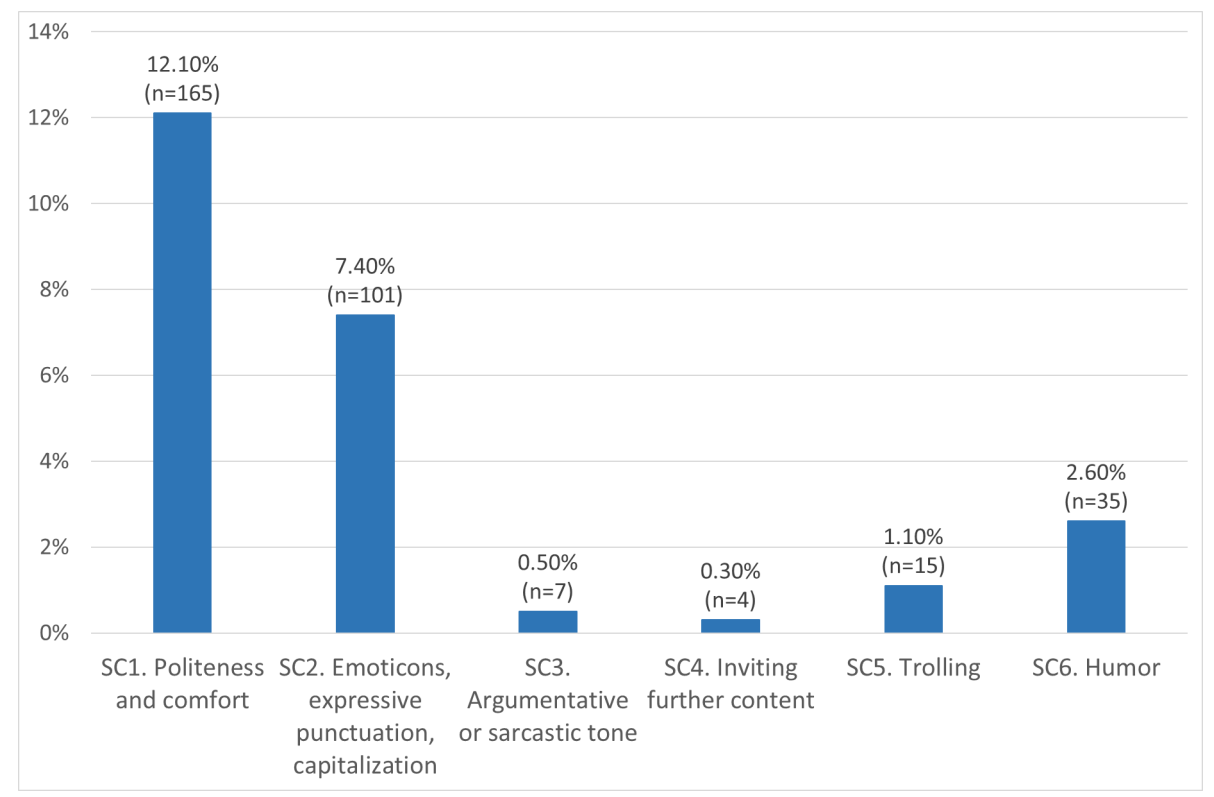

Figure 1. Distribution of social cues.

hosting an AMA, favorite and least favorite types of questions, lessons learned, and the reasons for agreeing to host an AMA. Specifically, the following five open-ended survey questions were used to gain a more nuanced understanding of scientists' experiences for this paper: "What types of questions did you most enjoy?"; "What types of questions did you least enjoy?"; "What did you like most about the experience?"; "What did you like least about the experience?"; and "What are the lessons you learned from your experience?"

\section{Findings}

\section{RQ1: What kinds of SCs are manifested in the AMA comments?}

An overview of each SC code is presented in Figure 1 (see also Table 3 in appendix A). Overall, $24 \%(n=327)$ of the total number of comments included SCs, some with multiple codes. The most frequently occurring code was SC1, Politeness and comfort $(n=165 ; 12.1 \%)$, signifying respectful and non-argumentative participants. Argumentation and sarcasm, represented by SC3, were relatively low ( $n=7 ; 0.5 \%)$; very seldomly were there "Hostile questions or off topic questions" [R24]. In only one instance was SC1 observed in tandem with SC3, possibly due to an attempted joke in AMA \#1, interpreted as argumentative. ${ }^{2}$ Similarly, SC5, Trolling, rarely occurred ( $n=15 ; 1.1 \%)$. One scientist said: "Reddit is not full of... trolls. There was genuine interest in the topic... and willingness to learn, not criticize" [R11]. SC3 and SC5 percentages were surprisingly low, considering the number of active commenters and subscribers to $\mathrm{r} /$ science. According to Renfro [2016], moderators are highly involved in monitoring discussions and deleting inappropriate comments, but even then, some go unnoticed. "A few comments were off-color. [The moderator] was monitoring for such comments, but a few snuck through." [R45]

\footnotetext{
${ }^{2}$ Guest: "I loved the Martian! As a space comm geek, I loved the sequence where establishing communications with Earth was a fundamental step in saving Matt Damon. I look forward to my real life opportunity to save Matt Damon." Participant: "His name is Mark Watney. Geez... Thanks for the reply man!"
} 
The second most frequent SC was SC2, Explicit emotional expression. Users seemed comfortable being informal when interacting with scientists. They used the following: Emoticons $(n=39 ; 60 \%)$; Internet-specific abbreviations $(n=6 ; 9.23 \%)$; Emphasized text $(n=21 ; 32.31 \%)$.

Finally, SC6, Humor, came up as the third most frequently-occurring SC. We applied this code to humor-filled, content-related posts unintended to derail the conversation, or intentionally wound recipients for fun. For example, a participant asked the guests in the Astronomy AMA (NASA's space communications) for the International Space Station's phone number, and we applied SC6 to the scientist's response: "867-5309". ${ }^{3}$ One scientist stated, "I think the tone you take in response to the questions is very important. The most successful Science AMAs... take a humble and humorous approach..." [R46]. However, another scientist observed, "some questions were on the humorous side, which was fun, but [what] we really wanted [was] a platform to answer questions about the science we are engaged in and... its implications" [R14].

Several posts exhibited instances of multiple SCs, most frequently SC1 and SC2, as many commenters thanked the guest scientists for participating and added smiley face emoticons, underscoring their pleasure interacting with them. Other code combinations included SC2 and SC6 when emoticons emphasized humorous comments, and SC1 and SC6 in posts exhibiting humor as well as guests or laypeople thanking one another for participating.

\section{RQ2: What variations of SCs are present across the different AMA science sessions?}

The percentages of total SCs in each AMA ranged from $17.7 \%(n=44)$ to $31.3 \%$ $(n=71)$ (see Figure 2). AMAs \#1 and \#6 had both the highest percentages of SCs and numbers of guest scientists (5 and 6, respectively). AMA \#5 had only one guest and the fewest number of guest responses, perhaps because the scientist meticulously crafted each answer.

Figure 3 summarizes the percentages of individual SCs in each AMA. The low number of SC3 demonstrates the participants' civility and engagement. Whenever there was a noticeable amount of SC3, more Trolling (SC5) appeared. For example, AMA \#1 had over $1 \%(n=3)$ of SC 3 , whereas other AMAs had 0 to $1 \%(n=1$ or 2$)$ of this code. Concurrently, AMA \#1 had 4.4\% $(n=10)$ of Trolling - four times more than in AMA \#2. AMA \#1's topic likely attracted more context-dependent trolls [Fichman and Peters, 2019], who commented phrases like "Where are you hiding the aliens?"

AMA \#3 and \#5's levels of Politeness and comfort were highest. In AMA \#5, users frequently thanked the guests, and they were polite even among themselves. When a user reacted to a suggestion with "Thanks, will read about it:)" the suggester responded, "Happy reading!" Similarly, one user in AMA \#3 ended a question with "Thank you for your response". These groups evidently established collegiality among themselves.

The next most frequent SC was the use ofemotional expressions. AMA \#1 included $10.1 \%(n=23)$ and AMA \#6 included $8.3 \%(n=21)$ of total comments related to

\footnotetext{
${ }^{3}$ A reference to the 1981 pop song by Tommy Tutone.
} 


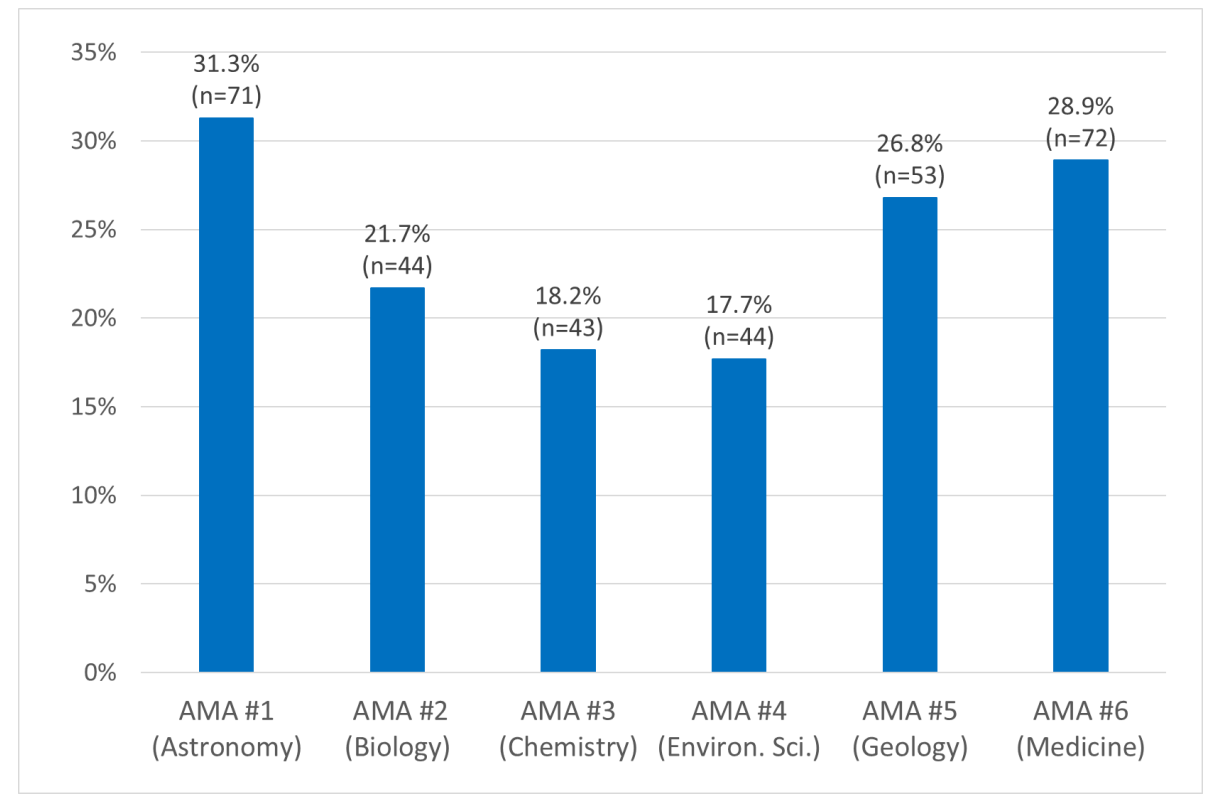

Figure 2. Percentage of total SCs in each AMA.

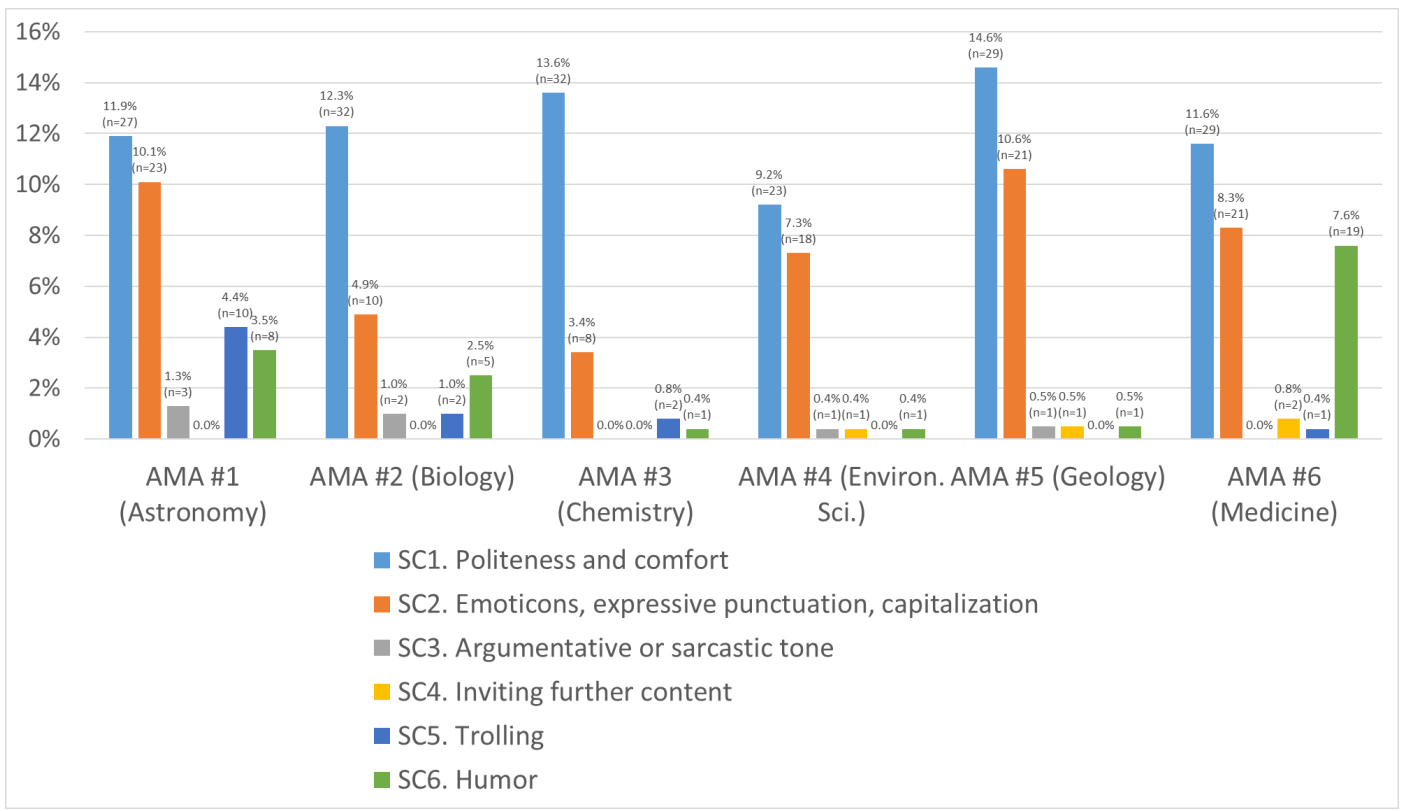

Figure 3. Percentage of individual SCs in each AMA.

emotional expressions. The use of emoticons was most apparent, the majority being smileys (i.e., :)), indicating the supportive and informal nature of the interactions.

While humor did not stand out in all analyzed AMAs, \#1 and \#6 had the most Humor codes. AMA \#1 featured NASA scientists discussing the Laser Communications Relay \& Demonstration (LCRD). Because of the references to laser beams, one guest scientist shared an Austin Powers-related meme and commented, "Reddit demands top quality OC and I will deliver: this is an UNOFFICIAL patch for LCRD. I hope I don't disinvite myself from being a federal employee", adding later, "I risk my career for a meme, and no upvotes :(". Memes 
AMA \#1

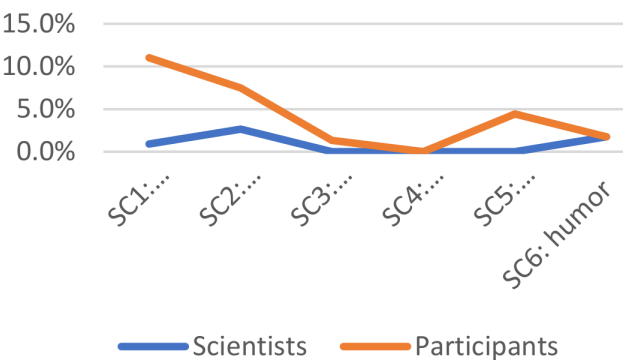

AMA \#3

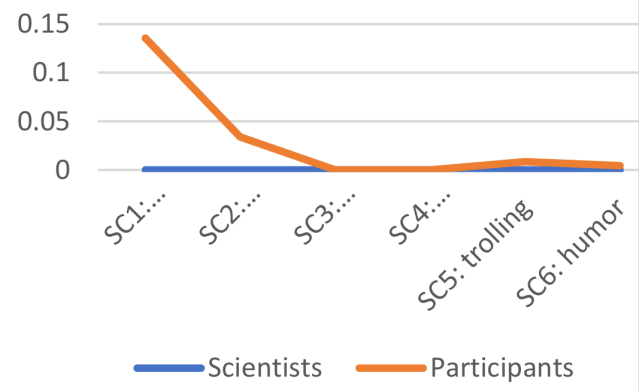

AMA \#5

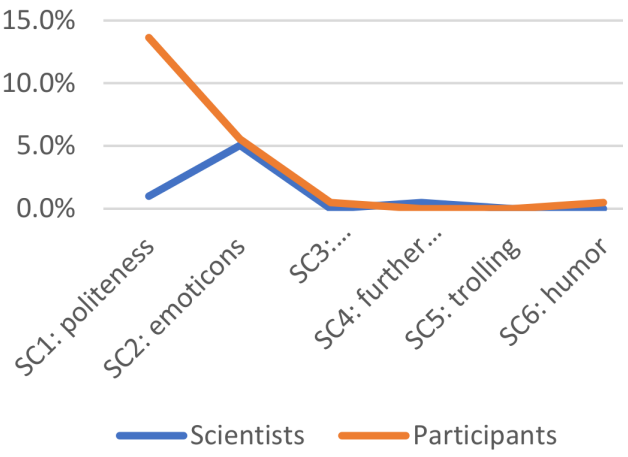

AMA \#2

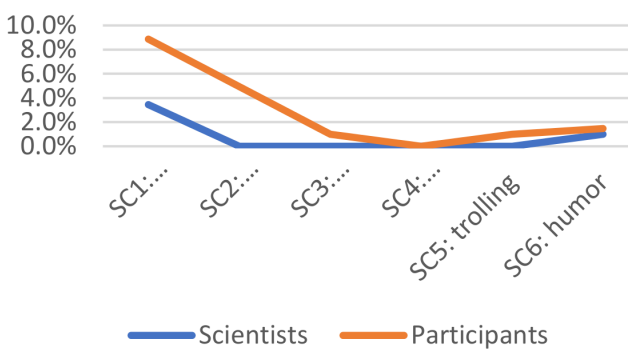

AMA \#4

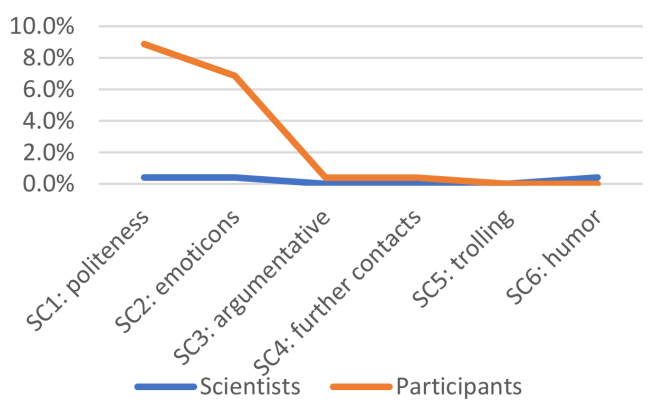

AMA \#6

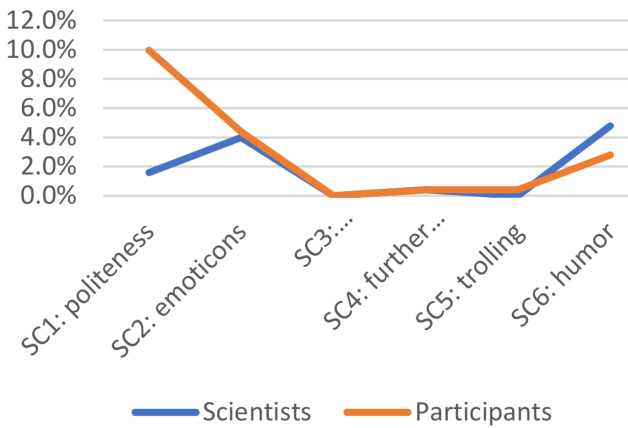

Figure 4. Social cues used by scientists and participants across the six AMAs.

are one of the most frequently performed activities [Massanari, 2015], and in this case did not appear to undermine the scientists' authority; rather, it made the scientists more approachable.

RQ3: How does the use of SCs by guest scientists affect that of audiences in the r/science AMA sessions?

Figure 4 summarizes the use of different SCs by scientists and participants across the six AMAs (also see Table 4).

Compared to participants, scientists exhibited fewer instances of overt politeness (SC1) in their posts. For the other SCs, when scientists used fewer SCs in their posts, the frequency of participants' SCs decreased in general. This is particularly 
evident in AMA \#3, where the guest scientist neglected to use any SCs, and the audience used only $4.7 \%(n=11)$ of non-politeness SCs in their responses, the lowest among all six AMAs. We noticed that most of the AMA \#3 guest responses were longer than those in the other five AMAs. Many were several paragraphs in length and most responses were complex and thorough. These long and complex responses may have contributed to a sense of seriousness and distance, and a consequential lack of casual and intimate expressions.

The participants contributed a fair amount of SC2 (Explicit emotional expression), ranging between $3.4 \%(n=8)$ and $7.5 \%(n=17)$; this was more than other SCs except politeness. However, scientists in some sessions (e.g., AMA \#2 and \#3) excluded SC2 in their posts, indicating that participants felt comfortable including their affect in their posts, regardless of the presence of emotional responses in scientists' responses. Furthermore, scientists in all six AMAs did not engage in any argumentative or trolling comments, as indicated by the low representation of SC3 or SC5. In three of the six AMAs, there were no SC4s (Inviting further contact).

The use of humor (SC6) by guest scientists seemed to encourage participants to act similarly. AMA \#6 saw the highest percentage of scientist and audience humor $(4.8 \%(n=12)$ and $2.8 \%(n=7)$, respectively). Although AMA \#4 and \#6 are the only two sessions in which scientists were more humorous than participants, the percentage in AMA \#4 was very small. Following this was AMA \#1, where both groups each employed $1.8 \%(n=4)$ of SC6 in their posts. Scientists' humor might have created a lighthearted and lively atmosphere in which participants were more prone to follow suit in their own communication.

Discussion

Before their discontinuation in May 2018 due to the significant decrease in participation after the change in Reddit's "upvote" algorithm, r/science AMAs were active for over five years and attracted many audiences. This venue was one of the few examples of technology-mediated science communication allowing direct communication with scientists. Not only were there two-way interactions between scientists and laypeople, informal spaces were offered so laypeople could casually participate. In a sense, $r$ /science AMAs aimed to give the impression that science is fun and exciting. Their success can be attributed to having been a component of a popular social media platform, and the relaxed atmosphere and use of lay language lowered the participation hurdle. Thus, Reddit is set apart from platforms that are more specific to science communication like ResearchGate, which supports interactions exclusively among researchers and presents itself as a community of practice for professionals [Wenger, 1998].

The higher percentages of SCs in these AMAs denote the informal nature of interactions between scientists and laypeople. The AMAs discussed here contained SCs consistent with their counterparts ResearchGate [Jeng et al., 2017] and Zhihu Live [Tang, Tian and Hara, 2019], whose communication occurs outside of existing organizations (e.g., universities). On the contrary, in official organizational settings, such as a FtF course and Moodle that included task-based online forum discussions, the percentages of SCs were lower [Sun et al., 2018; Zhu, 2012].

A surveyed researcher's comment appeared to agree that the presence and effectiveness of these SCs while discussing scientific topics indicates informal 
engagement: "Making questions [and answers] personal seemed to get a better response than technical answers" [R39].

Communication style affects online environments, especially discussions regarding intricate topics such as science. The variation in communication style could depend on the guests and users who participate in an individual AMA, i.e., groups consisting of polite people. Guests presenting SCs may also have encouraged reciprocation, ensuring acceptable informal communication. For example, AMA \#5 had only one guest and the fewest number of guest responses to user comments, yet the second highest number of SCs used by scientists. This guest gave the impression of being very personable and SCs may have been a priority for them. This is evident in the following post, "This has been a great discussion, thank you all for the great questions! I wish I had more time to answer even more questions, and to provide more thorough explanations! Follow me on social media for periodic updates on all things snow and ice! Be cool ;)". In this response, the guest could be perceived as a very friendly and approachable individual.

Regarding humor, both AMA \#6's guests and audience's SC6 percentage was the highest among the six AMA sessions. The second highest percentage of humor used by scientists was AMA \#1, tying with their audience. It seemed that the mix of scientists who participated in AMAs \#1 and \#6 were more comfortable using jokes and humor, evidently setting the stage for others to do the same. Another possible reason for the presence of humor might be that the guests of AMA \#6 included Ph.D. students who were likely younger and possibly more familiar and comfortable with online interactions and Reddit culture than other guests.

Finally, the topic could have made a difference in types of interactions. AMA \#1 focused on NASA/astronomy/astrophysics, a very popular subject due to shows like Star Trek and Cosmos. To some laypersons, working for NASA may seem more glamorous than other scientific careers. The perceived "coolness" of the topic might have boosted the numbers of "thank you" and "this is so great" posts.

In alignment with the literature [e.g., Janssen, IJsselsteijn and Westerink, 2014], positive SCs appeared to support the community's wellbeing in r/science AMAs. However, there are some concerns that the effectiveness of humor is questionable or that insider jokes may exclude outsiders [Riesch, 2015]; r/science's rules even specifically discourage the use of humor in posts. Negative SCs did not seem to impede technology-mediated science communication in $\mathrm{r}$ /science AMA sessions, partially given the low number of occurrences. If negative SCs were dominant, scientists might not want to participate in the future. This, however, does not seem to be the case; about half of the survey takers responded positively to a question about their openness to participating in a future AMA. Moderation is an important factor for successful online science communication [Yeo et al., 2019].

A potentially useful and positive outcome of two-way interactions between scientists and laypeople via venues like $\mathrm{r}$ /science AMAs is the encouragement of further scientific pursuits. Prior research shows that supporting students' interests is key to pursuing careers in health science [Boekeloo, Todaro Brooks and Qi Wang, 2017], engineering [Branch, Woodcock and Graziano, 2015], mathematics, physics, and chemistry [Aeschlimann, Herzog and Makarova, 2016]. Although it may not be intuitive for scientists, providing positive SCs is an important action by those who engage with the general public. 
The contributions of this study are twofold. Firstly, we examined an under-investigated, technology-mediated science communication site through the lens of SCs. Mendel and Riesch [2017] criticized the current status quo of online science communication as being ineffective, suggesting different approaches. In citing the U.K. government's Science: So What? So Everything campaign, which advocates for younger generations to pursue science-oriented careers, they observed that audiences of the campaign were more engaged in online environments featuring less authoritative and more humorous interactions between scientists and participants. They argued that this type of environment was more aligned with the idea of engagement than with one-way knowledge dissemination, which often leads to passive consumption of knowledge.

Likewise, gaining the general public's trust is a high priority for climate scientists [Goodwin and Dahlstrom, 2014]. In a literature review about effective communication strategies for climate change, they concluded that while humor and likeability in messaging could increase trust among some audiences, scientists should also embrace vulnerability to earn the public's trust while communicating science to the general public in a format like $\mathrm{r} /$ science AMAs. Scientists may employ one or more of the following strategies to make themselves vulnerable: "engaging with doubtful and dismissive audiences, undertaking burdens of proof to argue with them, empowering audiences to assess the science themselves, admitting error, and focusing on small issues" [Goodwin and Dahlstrom, 2014]. The SC of inviting future contact can explicitly encourage conversations. In this sense, the use of SCs in science communication can be a strategic solution to improving public trust in science. From this study, science communication practitioners can also learn to consider more intentional incorporation of SCs. At the same time, the question of how much SCs usage is appropriate remains and needs to be investigated further.

Secondly, we expanded upon prior studies that focus on positive aspects of SCs by incorporating negative SCs. We argue that examining both positive and negative aspects of SCs offers a more holistic understanding of online interactions and suggest this approach for future studies. In this study, we are challenging the standard model per a social informatics perspective [Kling, Rosenbaum and Sawyer, 2005]. This coding framework can be used in other settings to analyze how positive and negative SCs enhance or impede online Q\&A sites.

Mendel and Riesch [2017] claimed that the current practice of science communication in online environments is broken. While various online tools provide the potential for increased interaction and engagement between the public and scientists [Brossard, 2013], many existing formats of technology-mediated science communication are underutilized. Mendel and Riesch [2017] suggested breaking down the current practices of science communication by bringing in humor and playfulness. Despite being atypical science communication venues, $\mathrm{r}$ /science AMAs have created unexpected means for laypeople to engage with and become invested in science. Similarly, Massanari [2015] observed that play is one of the fundamental aspects of the Reddit community.

The $\mathrm{r}$ /science AMAs examined here appear to have functioned well as spaces for online science communication due to the affordances of the Reddit platform, including liberty of scientists to choose questions they answered, 
upvoting/downvoting, and expert-driven social Q\&As with non-expert contributions. These types of expert-driven social Q\&A sites have recently emerged and take advantage of both experts' and participants' knowledge for online science communication. In the words of one scientist, "Community involvement is extremely important - particularly for the young audience that Reddit AMA tends to attract" [R45]. Science communication practitioners may want to provide similar set-ups like $r$ /science AMA for encouraging engagement between scientists and laypeople.

Despite their popularity, $\mathrm{r}$ /science AMAs have not received much scholarly attention. The future development of online science communication platforms should consider learning from $\mathrm{r}$ /science AMAs. While $\mathrm{r}$ /science AMA has ceased its operation, Reddit AMAs that include scientists still continue. In addition, Reddit has another subreddit called "askscience" (i.e., r/science) that hosts threads such as Ask Anything Wednesday that solicit questions about specific disciplines. These are additional venues for investigating online science communication. Future studies also may examine science communication that involves interactions between scientists and laypeople on other social media platforms, such as YouTube channels and Facebook/Instagram live as well as on newer social media platforms such as Zhihui Live and Clubhouse.

Acknowledgments We thank the anonymous reviewers and Laura Schneider for their comments on earlier versions of this manuscript. 
Appendix A.

Social cues in the six AMAs
Table 3. Social cues.

\begin{tabular}{|c|c|c|c|c|c|c|}
\hline & $\begin{array}{l}\text { AMA \#1 } \\
\text { Astronomy }\end{array}$ & $\begin{array}{c}\text { AMA \#2 } \\
\text { Biology }\end{array}$ & $\begin{array}{l}\text { AMA \#3 } \\
\text { Chemistry }\end{array}$ & $\begin{array}{l}\text { AMA \#4 } \\
\text { Env. Sci. }\end{array}$ & $\begin{array}{l}\text { AMA \#5 } \\
\text { Geology }\end{array}$ & $\begin{array}{l}\text { AMA \#6 } \\
\text { Medicine }\end{array}$ \\
\hline $\begin{array}{l}\text { SC1. Politeness } \\
\text { \& comfort }\end{array}$ & $\begin{array}{c}27 \\
(11.9 \%)\end{array}$ & $\begin{array}{c}25 \\
(12.3 \%)\end{array}$ & $\begin{array}{c}32 \\
(13.6 \%)\end{array}$ & $\begin{array}{c}23 \\
(9.2 \%)\end{array}$ & $\begin{array}{c}29 \\
(14.6 \%)\end{array}$ & $\begin{array}{c}29 \\
(11.6 \%)\end{array}$ \\
\hline $\begin{array}{l}\text { SC2. Emoticons, } \\
\text { expressive } \\
\text { punctuations, etc. }\end{array}$ & $\begin{array}{c}23 \\
(10.1 \%)\end{array}$ & $\begin{array}{c}10 \\
(4.9 \%)\end{array}$ & $\begin{array}{c}8 \\
(3.4 \%)\end{array}$ & $\begin{array}{c}18 \\
(7.3 \%)\end{array}$ & $\begin{array}{c}21 \\
(10.6 \%)\end{array}$ & $\begin{array}{c}21 \\
(8.3 \%)\end{array}$ \\
\hline $\begin{array}{l}\text { SC3. } \\
\text { Argumentative } \\
\text { tone }\end{array}$ & $\begin{array}{c}3 \\
(1.3 \%)\end{array}$ & $\begin{array}{c}2 \\
(1.0 \%)\end{array}$ & $\begin{array}{c}0 \\
(0 \%)\end{array}$ & $\begin{array}{c}1 \\
(0.4 \%)\end{array}$ & $\begin{array}{c}1 \\
(0.5 \%)\end{array}$ & 0 \\
\hline $\begin{array}{l}\text { SC4. Inviting } \\
\text { future contact }\end{array}$ & $\begin{array}{c}0 \\
(0 \%)\end{array}$ & $\begin{array}{c}0 \\
(0 \%)\end{array}$ & $\begin{array}{c}0 \\
(0 \%)\end{array}$ & $\begin{array}{c}1 \\
(0.4 \%)\end{array}$ & $\begin{array}{c}1 \\
(0.5 \%)\end{array}$ & $\begin{array}{c}2 \\
(0.8 \%)\end{array}$ \\
\hline SC5. Trolling & $\begin{array}{c}10 \\
(4.4 \%)\end{array}$ & $\begin{array}{c}2 \\
(1.0 \%)\end{array}$ & $\begin{array}{c}2 \\
(0.8 \%)\end{array}$ & 0 & 0 & $\begin{array}{c}1 \\
(0.4 \%)\end{array}$ \\
\hline SC6. Humor & $\begin{array}{c}8 \\
(3.5 \%)\end{array}$ & $\begin{array}{c}5 \\
(2.5 \%)\end{array}$ & $\begin{array}{c}1 \\
(0.4 \%)\end{array}$ & $\begin{array}{c}1 \\
(0.4 \%)\end{array}$ & $\begin{array}{c}1 \\
(0.5 \%)\end{array}$ & $\begin{array}{c}19 \\
(7.6 \%)\end{array}$ \\
\hline Total social cues & $\begin{array}{c}71 \\
(31.3 \%)\end{array}$ & $\begin{array}{c}44 \\
(21.7 \%)\end{array}$ & $\begin{array}{c}43 \\
(18.2 \%)\end{array}$ & $\begin{array}{c}44 \\
(17.7 \%)\end{array}$ & $\begin{array}{c}52 \\
(26.8 \%)\end{array}$ & $\begin{array}{c}72 \\
(28.9 \%)\end{array}$ \\
\hline Total comments & 227 & 203 & 236 & 248 & 198 & 251 \\
\hline
\end{tabular}

Note: percentages were calculated by the number of comments for each code divided by the total number of all the comments (i.e., total in the bottom row).

Table 4. Social cues used by scientists and participants across the six AMAs.

\begin{tabular}{llccccccc}
\hline & $\begin{array}{c}\text { SC1: } \\
\text { politeness } \\
(\%)\end{array}$ & $\begin{array}{c}\text { SC2: } \\
\text { emotion } \\
(\%)\end{array}$ & $\begin{array}{c}\text { SC3: } \\
\text { argumen- } \\
\text { tative } \\
(\%)\end{array}$ & $\begin{array}{c}\text { SC4: } \\
\text { further } \\
\text { contacts } \\
(\%)\end{array}$ & $\begin{array}{c}\text { SC5: } \\
\text { trolling } \\
(\%)\end{array}$ & $\begin{array}{c}\text { SC6: } \\
\text { humor } \\
(\%)\end{array}$ & $\begin{array}{c}\text { Total } \\
(\%)\end{array}$ \\
\hline AMA1 & Scientists & $2(0.9 \%)$ & $6(2.6 \%)$ & 0 & 0 & 0 & $4(1.8 \%)$ & $12(3.5 \%)$ \\
& Participants & $25(11.0 \%)$ & $17(7.5 \%)$ & $3(1.3 \%)$ & 0 & $10(4.4 \%)$ & $4(1.8 \%)$ & $59(24.2 \%)$ \\
AMA2 & Scientists & $7(3.4 \%)$ & 0 & 0 & 0 & 0 & $2(1.0 \%)$ & $9(4.4 \%)$ \\
& Participants & $18(8.9 \%)$ & $10(4.9 \%)$ & $2(1.0 \%)$ & 0 & $2(1.0 \%)$ & $3(1.5 \%)$ & $35(17.2 \%)$ \\
AMA3 & Scientists & 0 & 0 & 0 & 0 & 0 & 0 & 0 \\
& Participants & $32(13.6 \%)$ & $8(3.4 \%)$ & 0 & 0 & $2(0.8 \%)$ & $1(0.4 \%)$ & $43(18.2 \%)$ \\
AMA4 & Scientists & $1(0.4 \%)$ & $1(0.4 \%)$ & 0 & 0 & 0 & $1(0.4 \%)$ & $3(1.2 \%)$ \\
& Participants & $22(8.9 \%)$ & $17(6.9 \%)$ & $1(0.4 \%)$ & $1(0.4 \%)$ & 0 & 0 & $41(16.5 \%)$ \\
AMA5 & Scientists & $2(1.0 \%)$ & $10(5.1 \%)$ & 0 & $1(0.5 \%)$ & 0 & 0 & $13(6.6 \%)$ \\
& Participants & $27(13.6 \%)$ & $11(5.6 \%)$ & $1(0.5 \%)$ & 0 & 0 & $1(0.5 \%)$ & $40(20.2 \%)$ \\
AMA6 & Scientists & $4(1.6 \%)$ & $10(4.0 \%)$ & 0 & $10(0.4 \%)$ & 0 & $12(4.8 \%)$ & $27(10.8 \%)$ \\
& Participants & $25(10 \%)$ & $11(4.4 \%)$ & 0 & $1(0.4 \%)$ & $1(0.4 \%)$ & $7(2.8 \%)$ & $45(17.9 \%)$ \\
\hline
\end{tabular}


Aeschlimann, B., Herzog, W. and Makarova, E. (2016). 'How to foster students' motivation in mathematics and science classes and promote students' STEM career choice. A study in Swiss high schools'. International Journal of Educational Research 79,pp. 31-41. https://doi.org/10.1016/j.ijer.2016.06.004.

Baxter, P. and Jack, S. (2008). 'Qualitative case study methodology: study design and implementation for novice researchers'. The Qualitative Report 13 (4), pp. 544-559. https://doi.org/10.46743/2160-3715/2008.1573.

Boekeloo, B. O., Todaro Brooks, A. and Qi Wang, M. (2017). ‘Exposures associated with minority high schoolers' predisposition for health science'. American Journal of Health Behavior 41 (2), pp. 104-113. https://doi.org/10.5993/AJHB.41.2.1.

Branch, S. E., Woodcock, A. and Graziano, W. G. (2015). 'Person orientation and encouragement: predicting interest in engineering research'. Journal of Engineering Education 104 (2), pp. 119-138. https://doi.org/10.1002/jee.20068.

Brossard, D. (2013). 'New media landscapes and the science information consumer'. Proceedings of the National Academy of Sciences 110 (Supplement 3), pp. 14096-14101. https://doi.org/10.1073/pnas.1212744110.

Burns, T. W., O'Connor, D. J. and Stocklmayer, S. M. (2003). 'Science communication: a contemporary definition'. Public Understanding of Science 12 (2), pp. 183-202. https://doi.org/10.1177/09636625030122004.

Chen, G. and Chiu, M. M. (2008). 'Online discussion processes: effects of earlier messages' evaluations, knowledge content, social cues and personal information on later messages'. Computers $\mathcal{E}$ Education 50 (3), pp. 678-692. https://doi.org/10.1016/j.compedu. 2006.07.007.

Chen, G., Chiu, M. M. and Wang, Z. (2012). 'Predicting social cues during online discussions: effects of evaluations and knowledge content'. Computers in Human Behavior 28 (4), pp. 1497-1509. https: //doi .org/10.1016/j . chb .2012.03.017.

Choi, E., Kitzie, V. and Shah, C. (2012). 'Developing a typology of online Q\&A models and recommending the right model for each question type'. Proceedings of the American Society for Information Science and Technology 49 (1), pp. 1-4. https://doi.org/10.1002/meet.14504901302.

Davies, S. R. (2008). 'Constructing communication: talking to scientists about talking to the public'. Science Communication 29 (4), pp. 413-434. https://doi.org/10.1177/1075547008316222.

Denzin, N. K. (2007). 'Triangulation'. In: The Blackwell encyclopedia of sociology. Ed. by G. Ritzer. Vol. 10. Malden, MA, U.S.A.: Blackwell. https://doi.org/10.1002/9781405165518. wbeost050.pub2.

Dudo, A. (2015). 'Scientists, the media, and the public communication of science'. Sociology Compass 9 (9), pp. 761-775. https://doi .org/10.1111/soc4.12298.

Einsiedel, E. F. (2014). 'Publics and their participation in science and technology: changing roles, blurring boundaries'. In: Routledge handbook of public communication of science and technology. Ed. by M. Bucchi and B. Trench. 2nd ed. New York, NY, U.S.A.: Routledge, pp. 125-139. https://doi.org/10.4324/9780203483794.ch10.

Fichman, P. and Peters, E. (2019). 'The impacts of territorial communication norms and composition on online trolling'. International Journal of Communication 13, pp. 1016-1035. 
Garrison, D. R., Anderson, T. and Archer, W. (1999). 'Critical inquiry in a text-based environment: computer conferencing in higher education'. The Internet and Higher Education 2 (2-3), pp. 87-105.

https://doi.org/10.1016/S1096-7516(00)00016-6.

Gauchat, G. (2012). 'Politicization of science in the public sphere: a study of public trust in the United States, 1974 to 2010'. American Sociological Review 77 (2), pp. 167-187. https://doi.org/10.1177/0003122412438225.

Gazan, R. (2011). 'Social Q\&A'. Journal of the American Society for Information Science and Technology 62 (12), pp. 2301-2312. https://doi .org/10.1002/asi. 21562.

Goodwin, J. and Dahlstrom, M. F. (2014). 'Communication strategies for earning trust in climate change debates'. Wiley Interdisciplinary Reviews: Climate Change 5 (1), pp. 151-160. https://doi.org/10.1002/wcc. 262.

Gunawardena, C. N. (1995). 'Social presence theory and implications for interaction and collaborative learning in computer conferences'. International Journal of Educational Telecommunications 1 (2), pp. 147-166.

Hara, N., Abbazio, J. and Perkins, K. (2019). 'An emerging form of public engagement with science: Ask Me Anything (AMA) sessions on Reddit r/science'. PLoS ONE 14 (5), e0216789. https://doi.org/10.1371/journal.pone.0216789.

Hara, N., Shachaf, P. and Hew, K. F. (2010). 'Cross-cultural analysis of the Wikipedia community'. Journal of the American Society for Information Science and Technology 61 (10), pp. 2097-2108. https: //doi .org/10.1002/asi.21373.

Huber, B., Barnidge, M., Gil de Zúñiga, H. and Liu, J. (2019). ‘Fostering public trust in science: the role of social media'. Public Understanding of Science 28 (7), pp. 759-777. https://doi.org/10.1177/0963662519869097.

Jang, S. M., Mckeever, B. W., Mckeever, R. and Kim, J. K. (2019). 'From social media to mainstream news: the information flow of the vaccine-autism controversy in the US, Canada, and the UK'. Health Communication 34 (1), pp. 110-117. https://doi.org/10.1080/10410236.2017.1384433.

Janssen, J. H., IJsselsteijn, W. A. and Westerink, J. H. D. M. (2014). 'How affective technologies can influence intimate interactions and improve social connectedness'. International Journal of Human-Computer Studies 72 (1), pp. 33-43. https://doi.org/10.1016/j.ijhcs.2013.09.007.

Jeng, W., DesAutels, S., He, D. and Li, L. (2017). 'Information exchange on an academic social networking site: a multidiscipline comparison on researchgate Q\&A'. Journal of the Association for Information Science and Technology 68 (3), pp.638-652. https://doi.org/10.1002/asi. 23692.

Jia, H., Wang, D., Miao, W. and Zhu, H. (2017). 'Encountered but not engaged: examining the use of social media for science communication by Chinese scientists'. Science Communication 39 (5), pp. 646-672. https://doi.org/10.1177/1075547017735114.

Jin, J., Li, Y., Zhong, X. and Zhai, L. (2015). 'Why users contribute knowledge to online communities: an empirical study of an online social Q\&A community'. Information \& Management 52 (7), pp. 840-849. https://doi.org/10.1016/j.im.2015.07.005.

Jones-Jang, S. M., Hart, P. S., Feldman, L. and Moon, W.-K. (2020). 'Diversifying or reinforcing science communication? Examining the flow of frame contagion across media platforms'. Journalism \& Mass Communication Quarterly 97 (1), pp. 98-117. https://doi.org/10.1177/1077699019874731. 
Jünger, J. and Fähnrich, B. (2020). 'Does really no one care? Analyzing the public engagement of communication scientists on Twitter'. New Media \& Society 22 (3), pp. 387-408. https://doi .org/10.1177/1461444819863413.

Kling, R., Rosenbaum, H. and Sawyer, S. (2005). Understanding and communicating social informatics: a framework for studying and teaching the human contexts of information and communication technologies. Medford, NJ, U.S.A.: Information Today.

Kotlyar, I. and Ariely, D. (2013). 'The effect of nonverbal cues on relationship formation'. Computers in Human Behavior 29 (3), pp. 544-551. https://doi.org/10.1016/j.chb.2012.11.020.

Kreuz, R. J. and Glucksberg, S. (1989). 'How to be sarcastic: the echoic reminder theory of verbal irony'. Journal of Experimental Psychology: General 118 (4), pp. 374-386. https://doi.org/10.1037/0096-3445.118.4.374.

Lee, N., Sha, B.-L., Dozier, D. and Sargent, P. (2015). 'The role of new public relations practitioners as social media experts'. Public Relations Review 41 (3), pp. 411-413. https://doi.org/10.1016/j.pubrev.2015.05.002.

Lévy-Leblond, J.-M. (1992). 'About misunderstandings about misunderstandings'. Public Understanding of Science 1 (1), pp. 17-21. https://doi.org/10.1088/0963-6625/1/1/004.

Mabry, E. A. (1997). 'Framing flames: the structure of argumentative messages on the net'. Journal of Computer-Mediated Communication 2 (4), JCMC241. https://doi.org/10.1111/j.1083-6101.1997.tb00193.x.

Marsh, O. (2016). "'People seem to really enjoy the mix of humour and intelligence": science humour in online settings'. JCOM 15 (02), C03. https://doi.org/10.22323/2.15020303.

Massanari, A. L. (2015). Participatory culture, community, and play: learning from Reddit. New York, NY, U.S.A.: Peter Lang. https://doi.org/10.3726/978-1-4539-1501-1.

Matias, J. N. (2019). 'The civic labor of volunteer moderators online'. Social Media + Society 5 (2). https: //doi .org/10.1177/2056305119836778.

McHugh, M. L. (2012). 'Interrater reliability: the kappa statistic'. Biochemia Medica 22 (3), pp. 276-282. https://doi .org/10.11613/BM. 2012.031.

Mendel, J. and Riesch, H. (2017). 'Gadflies biting science communication: engagement, tricksters, and ambivalence online'. Science Communication 39 (5), pp. 673-684. https://doi.org/10.1177/1075547017736068.

Oh, S. (2012). 'The characteristics and motivations of health answerers for sharing information, knowledge, and experiences in online environments'. Journal of the American Society for Information Science and Technology 63 (3), pp. 543-557. https://doi.org/10.1002/asi.21676.

Recabarren, M., Nussbaum, M. and Leiva, C. (2008). 'Cultural divide and the Internet'. Computers in Human Behavior 24 (6), pp. 2917-2926. https://doi.org/10.1016/j.chb.2008.04.013.

Reinig, B. A. and Mejias, R. J. (2004). 'The effects of national culture and anonymity on flaming and criticalness in GSS-supported discussions'. Small Group Research 35 (6), pp. 698-723. https://doi .org/10.1177/1046496404266773.

Renfro, K. (13th January 2016). 'For whom the troll trolls: a day in the life of a Reddit moderator'. Business Insider. URL: https : //www . businessinsider.com/w hat-is-a-reddit-moderator-2016-1.

Riesch, H. (2015). 'Why did the proton cross the road? Humour and science communication'. Public Understanding of Science 24 (7), pp. 768-775. https://doi.org/10.1177/0963662514546299. 
Rigutto, C. (2017). 'The landscape of online visual communication of science'. JCOM 16 (02), C06. https://doi .org/10.22323/2.16020306.

Rourke, L., Anderson, T., Garrison, D. R. and Archer, W. (1999). 'Assessing social presence in asynchronous text-based computer conferencing'. Journal of Distance Education 14 (2), pp. 50-71.

Sanfilippo, M., Yang, S. and Fichman, P. (2017). 'Trolling here, there, and everywhere: perceptions of trolling behaviors in context'. Journal of the Association for Information Science and Technology 68 (10), pp. 2313-2327. https://doi.org/10.1002/asi.23902.

Shachaf, P. and Hara, N. (2010). 'Beyond vandalism: Wikipedia trolls'. Journal of Information Science 36 (3), pp. 357-370. https://doi.org/10.1177/0165551510365390.

Shah, C., Kitzie, V. and Choi, E. (2014). 'Modalities, motivations, and materials investigating traditional and social online Q\&A services'. Journal of Information Science 40 (5), pp. 669-687. https : //doi .org/10.1177/0165551514534140.

Su, L. Y.-F., Scheufele, D. A., Bell, L., Brossard, D. and Xenos, M. A. (2017). 'Information-sharing and community-building: exploring the use of Twitter in science public relations'. Science Communication 39 (5), pp. 569-597. https://doi.org/10.1177/1075547017734226.

Sun, Z., Lin, C.-H., Wu, M., Zhou, J. and Luo, L. (2018). 'A tale of two communication tools: discussion-forum and mobile instant-messaging apps in collaborative learning'. British Journal of Educational Technology 49 (2), pp. 248-261. https://doi.org/10.1111/bjet.12571.

Tang, Y. and Hew, K. F. (2019). 'Emoticon, emoji, and sticker use in computer-mediated communication: a review of theories and research findings'. International Journal of Communication 13, pp. 2457-2483.

Tang, Y., Tian, H. and Hara, N. (2019). 'Mobile-based synchronous Q\&A for knowledge sharing: a case study of Zhihu Live'. In: ASIS\&T Regional Meetings - The Asia-Pacific Regional Conference (University of Cambodia, Phnom Penh, Kingdom of Cambodia, 3rd-4th January 2019).

Thacker, S. and Griffiths, M. D. (2012). 'An exploratory study of trolling in online video gaming'. International Journal of Cyber Behavior, Psychology and Learning 2 (4), pp. 17-33. https://doi.org/10.4018/ijcbpl.2012100102.

Walther, J. B. (1992). 'Interpersonal effects in computer-mediated interaction: a relational perspective'. Communication Research 19 (1), pp. 52-90. https://doi.org/10.1177/009365092019001003.

- (1996). 'Computer-mediated communication: impersonal, interpersonal, and hyperpersonal interaction'. Communication Research 23 (1), pp. 3-43. https://doi.org/10.1177/009365096023001001.

Wenger, E. (1998). Communities of practice: learning, meaning, and identity. New York, NY, U.S.A.: Cambridge University Press. https://doi.org/10.1017/CB09780511803932.

Weninger, T., Zhu, X. A. and Han, J. (2013). 'An exploration of discussion threads in social news sites: a case study of the Reddit community'. In: ASONAM '13: Proceedings of the 2013 IEEE/ACM International Conference on Advances in Social Networks Analysis and Mining, pp. 579-583. https://doi.org/10.1145/2492517.2492646.

Wilholt, T. (2013). 'Epistemic trust in science'. The British Journal for the Philosophy of Science 64 (2), pp. 233-253. https://doi.org/10.1093/bjps/axs007. 
Yeo, S. K., Su, L. Y.-F., Scheufele, D. A., Brossard, D., Xenos, M. A. and Corley, E. A. (2019). 'The effect of comment moderation on perceived bias in science news'. Information, Communication \& Society 22 (1), pp. 129-146. https://doi.org/10.1080/1369118x.2017.1356861.

Young, R., Tully, M. and Dalrymple, K. E. (2018). '\#Engagement: use of Twitter chats to construct nominal participatory spaces during health crises'. Information, Communication \& Society 21 (4), pp. 499-515. https://doi.org/10.1080/1369118x.2017.1301518.

Zhu, C. (2012). 'Student satisfaction, performance, and knowledge construction in online collaborative learning'. Educational Technology \& Society 15 (1), pp. 127-136.

Ziegele, M. and Jost, P. B. (2020). 'Not funny? The effects of factual versus sarcastic journalistic responses to uncivil user comments'. Communication Research 47 (6), pp. 891-920. https://doi.org/10.1177/0093650216671854.

Authors

Ying Tang is an Associate Professor of Educational Technology at the Faculty of Education, Southwest University. She did her postdoctoral work in Informatics at Indiana University, and received her doctoral degree in Educational Technology from the University of Hong Kong. Her research interests lie in student learning in technology-mediated environment, instructional design, and computer-mediated communication. She can be reached at: E-mail: yingtang@swu.edu.cn.

Jessica M. Abbazio holds a Ph.D. in Musicology and an M.A. in Music History \& Literature from the University of Maryland, College Park, an M.L.S. in Music Librarianship from Indiana University, Bloomington, and a B.M. in Music Education from George Mason University. She is an Assistant Librarian at the University of Minnesota, and her research in the fields of information science and librarianship has centered on public engagement, outreach, information literacy, and collection development. E-mail: jabbazio@umn.edu.

Timothy Khe Hew is the Associate Dean for Research Higher Degree in the Faculty of Education. He is also an associate professor of Information \& Technology Studies at The University of Hong Kong. E-mail: kfhew@hku.hk.

Noriko Hara is a professor of information science in the Luddy School of Informatics, Computing and Engineering at Indiana University, Bloomington. E-mail:nhara@indiana.edu.

\section{How to cite}

Tang, Y., Abbazio, J. M., Hew, K. F. and Hara, N. (2021). ‘Exploration of social cues in technology-mediated science communication: a multidiscipline analysis on 'Ask Me Anything (AMA)' sessions in Reddit r/science'. JCOM 20 (07), A04. https://doi.org/10.22323/2.20070204. 